\section{Potassium Nutrition and Moisture Stress Tolerance of Salvia}

\author{
D. Joseph Eakes ${ }^{1}$, Robert D. Wright ${ }^{2}$, and John R. Seiler ${ }^{3}$ \\ Department of Horticulture, Virginia Polytechnic Institute and State \\ University, Blacksburg, VA 24061
}

Additional index words. photosynthesis, transpiration, leaf conductance, water potential

Elevated $\mathrm{K}$ fertilization during bedding plant production may reduce irrigation demand and moisture stress during marketing and landscape establishment. Lindhauer (1985) indicated increasing K fertilizer concentration reduced transpirational water loss and decreased the influence of moisture stress on gas exchange for sunflower. The objective of this study was to determine the influence of $\mathrm{K}$ nutrition level on gas exchange of salvia (Salvia splendens F. Sellow 'Bonfire') during the onset of moisture stress.

Seed of salvia were sown on 11 Jan. 1988 and transplanted 14 days later into 500-ml plastic pots containing a 1 peat : 1 perlite $(\mathrm{v} /$ v) medium amended with $1 \mathrm{~kg}$ of Micromax (Sierra Chemical Co., Milpitas, Calif.) and $3 \mathrm{~kg}$ dolomitic limestone $/ \mathrm{m}^{3}$. Plants were grown in a glasshouse under long-day conditions [night interruption from 2200 to 0200 HR using incandescent lights providing $\approx 4$ $\mu \mathrm{mol} \cdot \mathrm{s}^{-1} \cdot \mathrm{m}^{-2}$ photosynthetic photon flux (PPF) at the top of the plant canopies] to extend vegetative growth. Potassium was applied with each watering at 75,300 , or $600 \mathrm{mg} \mathrm{K} /$ liter from $\mathrm{KCl}$. Each K solution also contained (in $\mathrm{mg} \cdot \mathrm{liter}^{-1}$ ) $200 \mathrm{~N}$ from $\mathrm{NH}_{4} \mathrm{NO}_{3}$ and $25 \mathrm{P}$ from phosphoric acid. Solutions were applied at the rate of $250 \mathrm{ml}$ at each watering to maintain constant root-zone concentrations of nutrients. Treatments were arranged in a randomized complete block design with eight single-plant (eight pots) replicates for each treatment.

Plants were irrigated at $0545 \mathrm{HR}$ and placed under supplemental lighting provided with 1000-W high-pressure sodium lamps. Levels of PPF ranged from 605 to $745 \mu \mathrm{mol} \cdot \mathrm{s}^{-1} \cdot \mathrm{m}^{-2}$ during gas exchange measurements. Net photosynthesis $(\mathrm{Pn})$, transpiration $(\mathrm{E})$, leaf conductance $\left(\mathrm{g}_{\mathrm{L}}\right)$, and internal $\mathrm{CO}_{2}$ concentration $(\mathrm{CI})$ were obtained using the LI-COR Model 6200 portable photosynthesis system (LI-COR, Lincoln, Neb.). Mean gas analyzer leaf chamber relative humidity, temperature, and $\mathrm{CO}_{2}$ concentration during measurements were $38 \% \pm 7 \% 27 \pm 2 \mathrm{C}$, and $360 \pm 27 \mathrm{mg} \cdot$ liter $^{-1}$, respectively. Mes-

Received for publication 9 Jan. 1990. The cost of publishing this paper was defrayed in part by the payment of page charges. Under postal regulations, this paper therefore must be hereby marked advertisement solely to indicate this fact.

'Former Graduate Student. Present address: Dept. of Horticulture, Auburn Univ., AL 36849.

${ }^{2}$ Professor.

${ }^{3}$ Assistant Professor, Dept. of Forestry. ophyll resistance to $\mathrm{CO}_{2}\left(\mathrm{r}_{\mathrm{m}}\right)$ was determined using the equation: $\mathrm{r}_{\mathrm{m}}=\mathrm{CI} / \mathrm{Pn}$ (Osonubi and Davies, 1980). Gas exchange measurements were made every $1.5 \mathrm{~h}$ on the same recently matured leaf of each plant from 0900 to $1630 \mathrm{HR}$ on $17 \mathrm{Mar}$. and from 0900 to 1200 HR on 18 Mar. 1988 (days 65 and 66 following seeding, respectively).

Three plants per treatment were randomly selected at 0630,1100 , and $1630 \mathrm{HR}$ on day I and 0630 and 1100 HR on day 11 to determine leaf water potential $\left(\psi_{\mathrm{L}}\right)$ with a pressure chamber (Scholander et al., 1965). Plants were harvested following the final physiological observations at $1200 \mathrm{HR}$ on day II to determine shoot dry weight and total leaf area. Data analyses for variance and mean comparisons were made using Tukey's studentized range test at $P=0.05$.

Greatest $E$ and $g_{\mathrm{L}}$ (Fig. 1) were observed from 1330 to $1630 \mathrm{HR}$ on day I for plants grown with $75 \mathrm{mg} \mathrm{K} /$ liter. There were no differences in $\mathrm{E}$ and $\mathrm{g}_{\mathrm{L}}$ during day I among plants grown at 300 or $600 \mathrm{mg} \mathrm{K} / \mathrm{liter}$. Similar reductions in $\mathrm{g}_{\mathrm{L}}$ and $\mathrm{E}$ during day $\mathrm{I}$ indicate the reductions in water loss with increasing $\mathrm{K}$ fertilizer concentrations were due to stomatal changes. Both $\mathrm{E}$ and $\mathrm{g}_{\mathrm{L}}$ were lower on day II than on day I, regardless of $\mathrm{K}$ fertilizer concentration, and declined over time. Plants fertilized with $600 \mathrm{mg}$ K/liter maintained higher $E$ and $g_{\mathrm{L}}$ than plants fertilized with $75 \mathrm{mg} \cdot$ liter $^{-1}$ at the two observations on day II after $0900 \mathrm{HR}$.

Pn throughout day I was higher for plants fertilized with $75 \mathrm{mg} \mathrm{K} /$ liter than for the other treatments, peaking at $20.9 \mu \mathrm{mol} \cdot \mathrm{s}^{-1} \cdot \mathrm{m}^{-2}$ at 1330 HR (Fig. 1). In contrast, plants receiving 300 and $600 \mathrm{mg} \mathrm{K} /$ liter reached a peak of only $13.9 \mu \mathrm{mol} \cdot \mathrm{s}^{-1} \cdot \mathrm{m}^{-2}$ at $1200 \mathrm{HR}$. On day II, Pn continued to decline regardless of $\mathrm{K}$ fertilizer concentration. Final Pn observations taken at $1200 \mathrm{HR}$ showed a greater Pn for plants fertilized with $600 \mathrm{mg} \mathrm{K} /$ liter than for plants fertilized with $75 \mathrm{mg} \cdot$ liter $^{-1}$. No differences in $r_{m}$ (data not shown) were detected among plants grown at the various $\mathrm{K}$ fertilizer concentrations over the two days, indicating differences in Pn were stomatal in nature.

Potassium fertilizer concentration did not influence $\psi_{\mathrm{L}}$ among treatments at any one observation time during the study (data not shown). However at $1100 \mathrm{HR}$ on day II, all plants fertilized with $75 \mathrm{mg} \mathrm{K} /$ liter and several plants with $\mathrm{K}$ at $300 \mathrm{mg} \cdot \mathrm{liter}^{-1}$ wilted at mean $\psi_{\mathrm{L}}$ of -0.84 and $-1.08 \mathrm{MPa}$, respectively. None of the plants with $600 \mathrm{mg}$
K/liter wilted; they had a mean $\psi_{\mathrm{L}}$ of -1.09 $\mathrm{MPa}$.

Mean total shoot dry weights were 4.8 , 5.6, and $4.5 \mathrm{~g}$ for plants fertilized with 75 , 300 , and $600 \mathrm{mg} \mathrm{K} /$ liter, respectively. Total leaf area was $15 \%$ greater for plants with $\mathrm{K}$ at $300 \mathrm{mg} \cdot$ liter $^{-1}$ than for those grown with 75 or $600 \mathrm{mg} \mathrm{K} /$ liter.

These results suggest increasing $\mathrm{K}$ fertilizer concentrations may improve the tolerance of salvia to moisture stress by reducing transpirational water loss and allowing Pn to continue to lower $\psi_{\mathrm{L}}$. However, $\mathrm{K}$ at 600 $\mathrm{mg} \cdot$ liter $^{-1}$ improved moisture stress tolerance at the expense of plant growth. Before recommendations can be made for use of increased $\mathrm{K}$ fertilizer concentrations, other Ksalt fertilizers, concentrations, and their impact on the environment must be evaluated.

\section{Literature Cited}

Lindhauer, M.G. 1985. Influence of K nutrition and drought on water relations and growth of sunflower (Helianthus annuus L.). Z. Pflanzenernaehr Bodenk. 148:654-669.

Osonubi, O. and W.J. Davies. 1980. The influence of plant water stress on stomatal control of gas exchange at different levels of atmospheric humidity. Oecologia 46:1-6.

Scholander, P.F., H.T. Hammel, E.D. Bradstreet, and E.A. Hemmingsen. 1965. Sap pressure in vascular plants. Science 148:339-346.

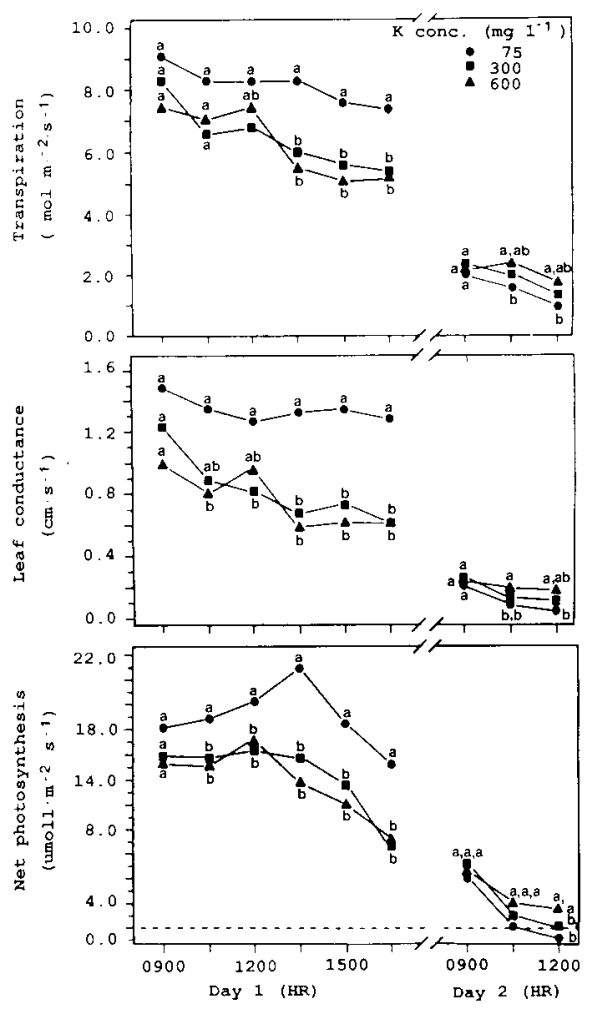

Fig. 1. Transpiration (top), leaf conductance (center), and net photosynthesis (bottom) per unit leaf area of Salvia splendens 'Bonfire' during the onset of moisture stress as influenced by $\mathrm{K}$ fertilizer concentration. Mean separation was made within each measurement time by $\mathrm{Tu}$ key's studentized range (HSD) test at $P=0.05$. 